\title{
perifèria
}

Número 13, diciembre 2010

www.periferia.name

\section{Preso y drogodependiente: doble estigma}

\author{
Rafael Clua García ${ }^{1}$
}

\section{Fornons Fontdevila, David (2009). Prisión y drogas: doble condena. Barcelona: deParís.}

David Fornons Fontdevila, tras varios años de trabajo en diferentes ámbitos del Centro Penitenciario de Hombres de Barcelona, La Modelo, ha realizado esta etnografía sobre las personas drogodependientes privadas de libertad. Ha conseguido desnudar su situación, abriéndonos las puertas de una institución de la que poco se habla y mucho menos cuando se asocia a los consumidores de drogas. El tema de las cárceles en España no es tratado con frecuencia en los medios de comunicación. Cuando se hace referencia casi siempre es para mostrar sus programas de rehabilitación o, en el peor de los casos, para hablarnos de los procesos judiciales de algunos famosos, presuntos delincuentes.

En esta etnografía, Fornons consigue desmitificar y definir claramente el contexto, sus estructuras y las personas que intervienen, sin caer en los tópicos y las típicas opiniones que brotan de una cosmología deformada sobre el fenómeno de la prisión. Con un lenguaje clarificador y bien documentado, Fornons nos entrega un trabajo, producto de su tesis doctoral El drogodependent empresonat a la Model de Barcelona: Narratives de la identitat fragmentada $i$ alternatives de Futur (2006). Este trabajo no pretende hacer una etnografía de la institución penitenciaria. Su objetivo es realizar una etnografía de las personas presas drogodependientes mostrándonos las narrativas sobre la realidad de la prisión: cómo viven, conviven, sobreviven; así como la construcción de la identidad y la cotidianidad dentro de la

\footnotetext{
1 Rafael Clua García: Licenciado y Máster en Antropología por la UAB. Enfermero en el Centro de Atención y Seguimiento a las Drogodependencias del Centro Penitenciario Brians 1 (Sant Esteve de Sesrovires, Barcelona). Enviar correspondencia a: cluag@msn.com
} 


\section{perifèria}

\section{Número 13, diciembre 2010}

www.periferia.name

prisión Modelo de Barcelona (Fornons, 2008: 171). La pregunta que se plantea es si el sistema penitenciario actual es capaz de asumir la función de rehabilitación y de reinserción de las personas drogodependientes que han cometido delitos.

David Fornons, diplomado en enfermería y trabajo social, y licenciado en antropología, es, como pocos, un privilegiado dentro de la institución penitenciaria. En el año 1992 comenzó a trabajar como enfermero en los programas de drogas del Departament de Justícia de la Generalitat de Catalunya, concretamente en el programa de mantenimiento con metadona del Centro penitenciario La Modelo. Más tarde pasó a impartir clases en el Departament d'Educació de la Generalitat de Catalunya como profesor de secundaria del mismo centro penitenciario. Esta sucesión en asistir, educar e investigar, nos demuestra que nos encontramos ante un experto sobre el significado de la institución penitenciaria en la sociedad actual. A su vez, Fornons imparte clases para la Universitat de Barcelona y es profesor asociado de la Universidad Nacional de Estudios a Distancia.

Las temáticas drogas y prisión han sido tratadas ampliamente por la antropología pero muy pocas veces de manera combinada. David Fornons desarrolla el marco teórico a partir de los pocos estudios que trabajan ambos conceptos, realizados en el marco de las instituciones penitenciarias de Catalunya. Apunta que estos no son suficientes al estar planteados desde perspectivas biomédicas o desde la criminología, por lo que sus conclusiones detallan una realidad fragmentaria. Se hace necesaria una ampliación teórica para trabajar la tríada contextos-sujetosdrogas nombrada por Zinberg (1984). Destacaríamos el uso de autores que han trabajado el binomio marginación y drogas (Aurelio Díaz, Oriol Romaní), autores que han trabajado el binomio marginación y prisión (Elena Larrauri, César Manzanos), y Julio Zino, que es de los pocos que en el marco español ha realizado estudios etnográficos sobre drogas y prisión. Desde una visión sistémica, trabaja el concepto persona utilizado por Ma Jesús Buxó (directora del doctorado que da resultado a esta etnografía), respaldado por el interaccionismo simbólico de Erving Goffman.

La obra se divide en seis partes: "Introducción", "Etnografiando la prisión", "La etnología en prisión", "El drogodependiente preso en La Modelo de Barcelona", 


\section{perifèria}

Número 13, diciembre 2010

www.periferia.name

"Narrativas de la identidad fragmentada" y "Expectativas de futuro". Desde un comienzo se sitúa al lector en los diferentes aspectos trabajados en la etnografía, para ir dando paso a las voces de las personas estudiadas: los drogodependientes presos de La Modelo. Los capítulos se acompañan de un prólogo a cargo de Julio Zino y Oriol Romaní, ambos expertos del medio estudiado, y del capítulo de la bibliografía utilizada.

En el primer capítulo, la "Introducción", se presentan cuáles son las dificultades de realizar una investigación en el medio penitenciario. No es uno de los medios más estudiados; en ocasiones, es difícil el acceso y las autorizaciones para investigar en él. David Fornons quizás, desde su posición, no tuvo dificultad para conseguir los permisos, aunque si se encontró con otro tipo de problemas. El cambio de rol y de posicionamiento podía desencadenar consecuencias no predecibles; investigar en tu lugar de trabajo puede ser arriesgado por los resultados que pueda dar la investigación.

Por otro lado, nos presenta la prisión como un contexto difícil de comprender. Expone que, desde la propia institución y los programas dirigidos a la población penitenciaria, se han creado unos objetivos que dificultan la búsqueda de necesidades y de beneficios para las personas privadas de libertad. En cualquier caso, el autor se plantea si realmente este trabajo etnográfico puede ser una antropología aplicable dentro de prisión. Desde su punto de vista, entiende la antropología como una ciencia holística que pretende comprender la realidad desde la ética. Su alegato es haber tenido el privilegio de estudiar un mundo clausurado desde esta visión, abogando por la potencialidad de esta ciencia. Una bocanada de aire fresco para las nuevas olas de antropólogos/as.

En el segundo capítulo, "Etnografiando la prisión", desarrolla el marco teórico y describe histórica y arquitectónicamente la prisión de hombres de Barcelona La Modelo. Define el tipo de investigación y la metodología del estudio. Se trata de un estudio cualitativo de tipo descriptivo-interpretativo a partir de las narrativas de los informantes. Estos, a lo largo del trabajo de campo, van cambiando hasta que se ajustaron a los objetivos de la investigación. Se realizaron historias de vida a quince personas, tratando el antes, el durante y las expectativas de futuro tras el 


\section{perifèria}

\section{Número 13, diciembre 2010}

www.periferia.name

encierro en prisión. A partir de las historias de vida, se realizó un análisis de contenido del discurso, apoyado por el diario de campo. Entre los informantes, encontramos cinco personas que entraban por primera vez en prisión, ocho que llevaban varias condenas cumplidas y dos ex reclusos. A cada uno de ellos se le realizaron cinco entrevistas planteando diferentes ejes temáticos de interés.

En gran parte del capítulo, desarrolla la operacionalización de los conceptos del estudio (a partir de la bibliografía empleada y en contraste con el contexto estudiado) necesaria para entender las ideas y teorías de la obra. Estos conceptos son: identidad, persona, cultura, drogadicción, marginación, delito y prisión. La puntualización de los diferentes conceptos es algo a tener en cuenta. Puede parecer que, dentro de una obra como ésta, no sea necesario este tipo de desarrollo, pero lo que nos quiere transmitir el autor es que no se deben utilizar los conceptos con definiciones cerradas o al libre albedrío. Cabe destacar el desarrollo del concepto cultura, concretamente cuando se habla de cultura carcelaria. Bajo el prisma de La interpretación de las culturas de Geertz (1973), Fornons responde que:

No existe una cultura carcelera en la prisión, acaso la ficción de una cultura carcelera o la implicación de la realidad social de lo que ocurre en la prisión.

(Pág. 48)

Además, introduce el concepto griego Oikos, utilizado y prestado por Buxó, para describirnos la prisión como un ecosistema, un lugar de convivencia.

En el tercer capítulo, "La etnología en prisión", elabora los fundamentos teóricos para el estudio de las narrativas de las personas estudiadas, comparando la vivencia en el oikos con el mundo exterior. El capítulo se desarrolla a partir del abordaje sistémico de Mo Jesús Buxó y el interaccionismo simbólico de Erving Goffman. Nos habla sobre los sistemas cognitivos de las personas presas y como éstas adoptan diferentes máscaras para la convivencia. Fornons consigue desmitificar el concepto prisionización, término erróneo utilizado para describir el proceso por el que las personas presas adoptan los valores de la cultura carcelaria o valores carceleros. Si anteriormente había fundamentado que no existe la cultura carcelera, ante la palabra prisionización responde que cabe hacer una rectificación y 


\section{perifèria}

Número 13, diciembre 2010

www.periferia.name

en todo caso hablar de adaptación. Este término es más adecuado y no se debe confundir con el concepto integración, pues estamos hablando de una imposición a convivir con personas con las que quizás no se quiere emprender la convivencia.

A mitad del capítulo desarrolla las particularidades del caso estudiado y cómo seleccionó a los informantes. Expone las peculiaridades del manejo del doble rol dentro de la institución. Cabe resaltar la sinceridad de Fornons al anteponer su amistad con las personas presas a la vinculación antropológica. También, el respeto y ética que demostró ante los informantes y el desarrollo habitual de la prisión.

En el cuarto capítulo, "El drogodependiente preso en La Modelo de Barcelona", se introducen las narrativas de los informantes, no sin antes desarrollar las implicaciones del Reglamento Penitenciario hacia la población reclusa. Los objetivos de éste son dos: el cumplimiento de la pena y la rehabilitación. Fornons, bajo diferentes argumentos, cuestiona lo segundo, sobre todo cuando se trata de la rehabilitación de drogodependientes. Expone que las personas drogodependientes presas tienen pocas alternativas para la elección de programas dirigidos al abordaje de las drogodependencias y que no existe un acuerdo en la intervención. Por ejemplo, habla del fracaso de la introducción de los programas de intercambio de jeringuillas, programas dirigidos a reducir los daños asociados al consumo de drogas por vía intravenosa, causado por la oposición de los funcionarios de vigilancia. Cabe decir que, desde que se realizó la investigación, las prisiones catalanas han sufrido cambios; se ha implantado el programa de intercambio de jeringuillas en casi todas las prisiones, excepto en La Modelo donde existe una mayor oposición al programa. Asimismo, se han implantado dos Centros de Atención y Seguimiento a las Drogodependencias en las prisiones de cumplimiento de Brians 1 y 2 (Sant Esteve de Sesrovires, Barcelona). Se han producido cambios, pero la Modelo sigue reacia a estos.

A mitad del capítulo se realiza una presentación de los informantes y la explicación de su cotidianidad, reflejando la marginación y la drogodependencia en la que viven. Analiza la estigmatización de las personas estudiadas tildadas de yonki: palabra utilizada en el argot para denominar a las personas drogodependientes que 


\section{perifèria}

Número 13, diciembre 2010

www.periferia.name

usan drogas por vía intravenosa. Fornons concluye:

El yonki es la identidad fragmentada que posee el drogodependiente preso y en la prisión tendrá que adaptarse y crearse otra nueva identidad. (Pág. 145)

En el quinto capítulo, "Narrativas de la identidad fragmentada", se expone ampliamente la cotidianidad y las narrativas de los informantes. Primero, describe el funcionamiento y los horarios habituales de un día en el oikos, la prisión Modelo. Para ello, Fornons nos habla de la convivencia entre presos bajo el concepto de la reciprocidad. Refleja la desconfianza y el miedo que se vive entre presos; la prisión es un lugar donde es difícil confiar y donde sólo vale la supervivencia. Después, se detallan los diferentes personajes que conviven en un mismo espacio: personal de vigilancia, junta de tratamiento (psicólogos, educadores, etc.), servicios médicos y los presos. Fornons nos habla de dos tipos de presos: los kíes y los chivatos. El kíe es el preso que toma protagonismo y que se comporta como líder, capaz de dirigir ciertos funcionamientos de la prisión. El chivato es el preso que informa a los funcionarios de vigilancia sobre otros presos. Con la aparición de estos, la figura del kíe ha perdido fuerza porque, actualmente, la colaboración con los funcionarios está bien vista por la institución, aunque incomode al resto de presos. Ambos son métodos de supervivencia como seria buscarse la vida: mantener un consumo activo de drogas en un contexto adverso. Se describen las diferentes estrategias para conseguir drogas dentro de prisión y cómo burlar la evidencia de consumir ante la junta de tratamiento, responsables de valorar los beneficios penitenciarios: permisos, comunicaciones, etc.

A continuación, se habla de la relación con el otro preso y el otro institucional, los funcionarios de vigilancia. Para relacionarse con el resto de personas presas y con los funcionarios, se habla del uso de máscaras en el escenario de la prisión. Existen muchas alertas y es necesario actuar de forma adaptada para superar la experiencia de la convivencia en prisión. Ante el otro institucional se habla de tres tipos de funcionarios de vigilancia, según un informante: "el provocador o perseguidor, el cuartelero que te da cuartelillo y luego el que viene a hacer sus ocho horas pasa de todo y se va" (pág. 187). 


\section{perifèria}

Número 13, diciembre 2010

www.periferia.name

El capítulo se cierra con las propuestas de los informantes para un cambio de la situación de las personas drogodependientes presas. Se plantea si la prisión es necesaria para este tipo de población y si se podría dar otro tipo de abordajes. Las respuestas son de lo más variopinto, pero todas son contrarias al funcionamiento actual del contexto penitenciario.

Finalmente, en el sexto capítulo, "Expectativas de futuro", Fornons recoge las conclusiones y propuestas del resultado de su investigación. Expone, de manera resumida, la marginalidad en la que viven los informantes y los infortunios que se han ido encontrando a lo largo de sus historias de vida. Son personas con dificultades en la participación social y tras su paso por prisión, sus oportunidades son aún menores. Una de las conclusiones es que el proceso rehabilitador y de reinserción de la prisión falla, ya desde la justicia infantil y juvenil. Son personas que han estado marcadas desde siempre por la tríada marginación, drogas y delito.

Fornons propone redefinir aquellos conceptos mal formulados que potencian los mitos creados en prisión, así como los conceptos ligados a la psiquiatría que estigmatizan a las personas drogodependientes. Propone redefinir y desmitificar los conceptos cultura carcelaria y prisionización; conceptos utilizados en el vocabulario de la prisión y que a lo largo de la obra se han ido diseccionando para acabar vacíos de significado. Por otro lado, habría que redefinir los conceptos sociopata o patología dual y valorar si las personas tildadas por estos términos deberían cumplir sus penas en otro tipo de establecimiento. Finalmente, propone cambios en los equipos de profesionales de la prisión. Propone evaluar los equipos de tratamiento $y$ de funcionarios de vigilancia $y$, en el caso de la atención a drogodependientes, sugiere que esté dirigida por equipos multidisciplinares especializados en drogodependencias. Es necesaria una consecución de la educación, sanidad e intimidad dentro de prisión y continuar revisando el caso del drogodependiente en prisión.

Afirmaremos que nos encontramos ante una obra única de un antropólogo que, como Goffman, puso en práctica el doble rol dentro de una institución total, en este caso la prisión. Ha sido interesante la exposición de las narrativas de las personas drogodependientes presas, presentadas como un grupo social portador de un 


\section{perifèria}

Número 13, diciembre 2010

www.periferia.name

estigma. Estas utilizarán diferentes estrategias para sobrevivir en un medio constantemente vigilado. Estas personas no acaban de adaptarse y continúan sin tener participación en el diseño de los programas orientados al tratamiento de las drogodependencias. Si realmente se quiere conseguir los objetivos de la institución (la rehabilitación y la reinserción) será necesario valorar la opinión de las personas interesadas.

Las narrativas de las personas estudiadas nos manifiestan la dureza de sus vidas y de cómo a lo largo de sus carreras morales, nos topamos con unas identidades fragmentadas que se adaptan, pero que no colaboran con el medio que les ha sido impuesto. La persona drogodependiente, tras su paso por la institución penitenciaria, no gana calidad de vida, su situación empeora. La persona drogodependiente es portadora de un estigma $y$, en ocasiones, tiene que manejar información de su biografía para ocultar sus atributos desacreditadores. Una vez entra en prisión continúa el enmascaramiento, y tras la salida de prisión, además de continuar manejando su condición de drogodependiente, deberá manejar su condición de expresidiario: el binomio drogas y prisión es una doble condena, ser preso y drogodependiente produce un doble estigma.

Es una obra que debería conocer todo técnico o profesional de prisiones. Nos describe la precariedad de la situación de los drogodependientes presos y reclama una reforma, tanto en los programas dirigidos al tratamiento de las drogodependencias, como en el proceso judicial de estas personas. Intrínsecamente, la obra puede ayudar al personal penitenciario a posicionarse y cuestionarse cuál es realmente su función. Quizás puedan llegar a comprender mejor el problema de las personas con las que trabajan.

Finalmente, resaltar la valentía de David Fornons por haber intervenido desde su lugar de trabajo y enseñarnos cuál es la situación de muchas de las personas que cumplen condena, sobre todo de aquellas de las que nunca se habla. Quizás, en un futuro, sea necesario dar continuidad a este trabajo y etnografiar a los profesionales, técnicos, jueces, etc., de las instituciones penitenciarias y judiciales. Los resultados podrían ser orientativos para un cambio de dirección en la intervención y se podría mejorar la calidad de vida de los colectivos más 


\section{perifèria}

Número 13, diciembre 2010

www.periferia.name

necesitados.

\section{Bibliografía}

Fornons, David (2007) El drogodependent empresonat: narratives de la identitat fragmentada i alternatives de futur, Revista d'etnologia de Catalunya, no 30, 171172.

(2008) Etnografia de la presó o etnografia de les persones preses? Revista d'etnologia de Catalunya, no 33, 106-115.

Goffman, Erving (1994 [1961]) Internados. Ensayos sobre la situación social de los enfermos mentales. Buenos aires: Amorrortu.

(2001 [1963]) Estigma. La identidad deteriorada. Buenos Aires: Amorrortu. 